\title{
Atributos de solo sob pastejo rotacionado em função da aplicação de cama de peru'
}

\author{
Flávio Araújo Pinto 2 , Franciane Lemes dos Santos 3 , Flávia Dias Terra ${ }^{3}$, Diego Oliveira Ribeiro ${ }^{4}$, Renata Rodrigues \\ Jardim Sousa ${ }^{3}$, Edicarlos Damacena de Souza ${ }^{4}$, Marco Aurélio Carbone Carneiro ${ }^{5}$, Helder Barbosa Paulino ${ }^{3}$
}

\begin{abstract}
Properties of soil under rotational grazing

system submitted to turkey litter application

Poultry litter applications can improve biological, physical, and chemical soil attributes. This study aimed at evaluating the effect of sequential turkey litter doses on properties of soil under a rotational grazing system with Brachiaria decumbens L., in Portelândia, Goiás State, Brazil. The experiment was carried out in a split-plot randomized blocks design, with four replications. Treatments consisted of turkey litter doses [no litter, 8.7 $\mathrm{Mg} \mathrm{ha}^{-1}$ (2008), 16.5 $\mathrm{Mg} \mathrm{ha}^{-1}$ (2008 + 2009), and $30.9 \mathrm{Mg} \mathrm{ha}^{-1}(2008+2009+2010)$ ], for plots, with the two highest doses resulting from the accumulation of litter applications, and three sampled soil depths $(0-5 \mathrm{~cm}, 5-10 \mathrm{~cm}$, and $10-20 \mathrm{~cm}$ ), for split-plots. Sequential applications of turkey litter doses improved soil fertility, increasing the $\mathrm{pH}, \mathrm{P}, \mathrm{K}$, and base saturation rates, as well as organic carbon, total and particulate nitrogen contents, and decreasing aluminum saturation. Lower doses of turkey litter stimulated the soil microbial activity, promoting the mineralization of the organic matter particulate fraction, however, there was no effect on soil aggregation.
\end{abstract}

KEY-WORDS: Brachiaria decumbens L.; poultry litter; organic fertilizing.

\section{INTRODUÇÃO}

A região do Cerrado destaca-se no cenário agropecuário nacional como importante pólo produtor de carnes, em especial de aves. No entanto, a produção de aves gera grande quantidade de resíduos, que devem ter destino apropriado, a fim de não contaminar o ambiente. Neste sentido, os resíduos da produção de aves, como a cama de peru, podem ser

\section{RESUMO}

Adições de dejetos de aviário podem promover melhorias nos atributos biológicos, físicos e químicos do solo. O presente estudo objetivou avaliar os efeitos de doses sequenciais de cama de peru nos atributos de solo sob pastejo rotacionado com Brachiaria decumbens L., em Portelândia (GO). O delineamento utilizado foi em blocos casualizados, em esquema de parcela subdividida, com quatro repetições. Os tratamentos alocados nas parcelas foram doses de cama de peru [ausência de adubação; 8,7 $\mathrm{Mg} \mathrm{ha}^{-1}$ (2008); 16,5 $\mathrm{Mg} \mathrm{ha}^{-1}$ (2008 + 2009); $\left.30,9 \mathrm{Mg} \mathrm{ha}^{-1}(2008+2009+2010)\right]$, sendo que as duas maiores doses resultaram do acúmulo das aplicações de dejeto. Como subparcelas, foram consideradas as profundidades amostradas (0-5 cm, 5-10 cm e 10-20 cm). Aplicações sequenciais de cama de peru promoveram melhorias na fertilidade do solo, com aumento de $\mathrm{pH}, \mathrm{P}, \mathrm{K}$, saturação por bases e estoque de carbono orgânico, nitrogênio total e particulado e diminuição na saturação por alumínio. A aplicação de menores doses de cama de peru estimulou a atividade microbiana do solo, promovendo a mineralização da fração particulada da matéria orgânica, porém, não houve efeito na agregação do solo.

PALAVRAS-CHAVE: Brachiaria decumbens L.; dejeto de aviário; adubação orgânica.

utilizados como fertilizantes em lavouras e, de forma mais restrita, em pastagens (Andreola et al. 2000).

A cama de peru pode conter inóculo de patógenos (Encefalopatia Espongiforme Transmissível EET) e, por este motivo, o pastoreio por animais, em pastagens fertilizadas com a mesma, deve ocorrer 40 dias após a sua aplicação, conforme previsto na Instrução Normativa ${ }^{\circ} 25$ de 23/07/2009, do Ministério da Agricultura (Brasil 2009). No entanto,

1. Trabalho recebido em mar./2012 e aceito para publicação em ago./2012 ( ${ }^{\circ}$ registro: PAT 17543).

2. Escola Superior de Agricultura Luiz de Queiroz (ESALQ), Departamento de Ciência do Solo, Piracicaba, SP, Brasil.

E-mail: flavioaraujo10@gmail.com.

3. Universidade Federal de Goiás (UFG), Campus de Jataí, Jataí, GO, Brasil.E-mails: franciane_lemes@hotmail.com, flavinha_agro@hotmail.com, renatajardimagro@hotmail.com, helderlino51@yahoo-com.br.

4. Universidade Federal Rural de Pernambuco (UFRPE), Departamento de Agronomia, Recife, PE, Brasil.

E-mails: diegoribe@yahoo.com.br, edicarlos@pq.cnpq.br.

5. Universidade Federal de Lavras (UFLa), Departamento de Ciência do Solo, Lavras, MG, Brasil. E-mail: carbonecarneiro@yahoo.com.br. 
estes materiais estão, muitas vezes, disponíveis nas propriedades a baixo custo, ocorrendo aplicações sem embasamento científico.

O dejeto de aviário, no qual se inclui a cama de peru, é rico em nutrientes, e a sua aplicação tem sido associada à melhorias nos atributos químicos, físicos e biológicos do solo (Costa et al. 2009), elevando, muitas vezes, o $\mathrm{pH}$ e aumentando a fertilidade do solo (Whalen et al. 2000, Scherer et al. 2010). Scherer et al. (2007) evidenciaram aumento na disponibilidade de nutrientes às plantas; melhoria na qualidade física do solo, devido à redução da erosão e aumento na retenção de água; e melhoria na qualidade biológica do solo, devido ao aumento nos teores de carbono e nitrogênio (Bayer et al. 2004).

A baixa produção de resíduos vegetais em sistemas agrícolas pode promover a redução do carbono orgânico nativo (Corazza et al. 1999). Sistemas agrícolas que promovem alta adição de resíduo ao solo, tanto vegetal como animal, proporcionam aumento nos estoques de matéria orgânica do solo (MOS). Isto decorre das menores perdas de solo por erosão e do aumento da atividade microbiana, a qual favorece melhorias na agregação, com consequente proteção física da MOS (Souza et al. 2009). Desta forma, com a aplicação de resíduos da produção de aves em superfície, é possível aumentar os estoques de MOS, principalmente quando a aplicação é sequencial e em altas quantidades, pois, além do fornecimento de carbono, ocorre aumento na produção de resíduos, pelas culturas.

Além dos atributos químicos e biológicos do solo, a utilização de dejetos de aviário afeta seus atributos físicos, como a estrutura. Costa et al. (2009) constataram que, com a utilização de doses crescentes de dejeto de aviário em pastagem, ocorrem aumentos de agregados maiores que 2,0 $\mathrm{mm}$ e redução de agregados menores que $0,25 \mathrm{~mm}$, contribuindo para a melhoria dos atributos físicos do solo.

Grande parte dos trabalhos realizados com dejeto de aviário tem focado a cama de frango, no entanto, poucos estudos têm abordado a cama de peru. Portanto, espera-se que a aplicação de cama de peru promova elevação do $\mathrm{pH}, \mathrm{P}$ e K, além de influenciar na agregação do solo, estoque de carbono e atividade microbiana. Desta forma, este trabalho objetivou avaliar os efeitos da aplicação de cama de peru sobre os atributos físicos, químicos e biológicos de solo sob pastejo rotacionado.

\section{MATERIAL E MÉTODOS}

O experimento foi desenvolvido na Fazenda Alvorada, localizada em Portelândia (GO). A região apresenta temperatura média anual de $24,2^{\circ} \mathrm{C}$ e precipitação pluviométrica média de $1.700 \mathrm{~mm}$. O clima predominante é quente, semiúmido e notadamente sazonal, com verão chuvoso e inverno seco, sendo classificado como "Aw", conforme a classificação de Köppen.

O solo da área experimental foi caracterizado como Latossolo Vermelho distroférrico $\left(739 \mathrm{~g} \mathrm{~kg}^{-1}\right.$ de argila, $125 \mathrm{~g} \mathrm{~kg}^{-1}$ de silte e $136 \mathrm{~g} \mathrm{~kg}^{-1}$ de areia, na camada 0-20 cm), cultivado com Brachiaria decumbens, para bovinocultura de leite, em sistema de pastejo rotacionado. A área foi composta por 16 piquetes de 0,5 ha, manejados com dois dias de ocupação e 30 dias de descanso. Os piquetes foram ocupados por 20-25 bovinos da raça Girolando, no período chuvoso, com peso vivo variando entre $550 \mathrm{~kg}$ e $600 \mathrm{~kg}$. No período seco, os animais foram tratados com silagem, durante o dia, e, no período noturno, colocados na referida área, para pastejar. A implantação da pastagem ocorreu em 1995 e, nos 10 anos anteriores à condução do experimento, não houve correção de acidez e adubação do solo.

O resíduo aplicado ao solo foi oriundo de dejetos provenientes da criação de peru, com cama à base de maravalha, apresentando a seguinte composição (média dos três anos de aplicação): C-orgânico = $308 \mathrm{~g} \mathrm{~kg}^{-1} ; \mathrm{N}=3,2 \% ; \mathrm{P}_{2} \mathrm{O}_{5}=3,5 \% ; \mathrm{K}_{2} \mathrm{O}=2,5 \%$; $\mathrm{Ca}=4,0 \% ; \mathrm{Mg}=0,9 \%$; relação $\mathrm{C}: \mathrm{N}=10 / 1$; matéria seca $=73,3 \% ; \mathrm{pH}$ em água $=7,7$.

O experimento iniciou-se em 2008, com a primeira aplicação da cama de peru. O delineamento experimental adotado foi o de blocos casualizados, com quatro repetições, sendo cada parcela um piquete de 0,5 ha. As doses de cama de peru foram consideradas como parcela principal e as profundidades como subparcelas. A parcela principal foi constituída por doses anuais de cama de peru, aplicadas em anos consecutivos, no mês de outubro, nas seguintes doses: $0 \mathrm{Mg} \mathrm{ha}^{-1}$ (ausência de adubação), $8,7 \mathrm{Mg} \mathrm{ha}^{-1}$ (2008), 16,5 $\mathrm{Mg} \mathrm{ha}^{-1}\left(2008\right.$ + 2009) e 30,9 $\mathrm{Mg} \mathrm{ha}^{-1}$ $(2008+2009+2010)$, sendo as duas maiores doses resultantes do acúmulo das aplicações sequenciais. A subparcela foi constituída pelas profundidades de 0-0,05 m, 0,05-0,10 m e 0,10-0,20 m. A cama de peru foi aplicada superficialmente a lanço, com o auxílio de uma calcareadora, no início da estação chuvosa 
de cada ano, e, após aplicação, a pastagem ficou em descanso por 45 dias. Após este período, ocorreu a entrada dos animais, para pastejo.

No início do período seco de 2011, foram abertas trincheiras de $0,40 \mathrm{~m} \times 0,40 \mathrm{~m} \times 0,40 \mathrm{~m}$ e, com o auxílio de espátula, foi realizada a coleta de solo. As amostras para análise química foram colocadas em sacos plásticos, identificadas e levadas ao laboratório, onde foram colocadas em recipientes para secagem em estufa, a $45^{\circ} \mathrm{C}$, e, posteriormente, peneiradas. As amostras para avaliação microbiológica foram colocadas em sacos plásticos, identificadas e, posteriormente, acondicionadas em caixas térmicas, para encaminhamento ao laboratório, onde foram peneiradas e armazenadas em geladeira.

A amostragem para avaliação da agregação do solo foi realizada retirando-se blocos de solo indeformados, com dimensões de $0,15 \mathrm{~m}$ x $0,10 \mathrm{~m} \times 0,05 \mathrm{~m}$, com posterior envolvimento em filme de PVC, para manter a estabilidade da estrutura, os quais foram colocados em sacos plásticos, identificados e acondicionados em caixas de papelão, para transporte. No laboratório, após a retirada do filme de PVC, as amostras foram umedecidas e destorroadas em seus pontos de fraqueza e dispostas para secagem ao ar.

As análises e determinações realizadas foram as seguintes: carbono orgânico total e nitrogênio total (Tedesco et al. 1995), carbono na biomassa microbiana (Vance et al. 1987), nitrogênio na biomassa microbiana (Vance et al. 1987, Tedesco et al. 1995), respiração microbiana (Alef \& Nannipieri 1995) e quociente metabólico (Anderson \& Domsh 1993). O fracionamento físico da matéria orgânica (MO) foi realizado segundo Cambardella \& Elliot (1992), onde $20 \mathrm{~g}$ de solo e $80 \mathrm{~mL}$ de solução de hexametafosfato de sódio $\left(7,5 \mathrm{~g} \mathrm{~L}^{-1}\right)$ foram agitados durante 16 horas, em agitador horizontal. A seguir, a suspensão foi passada em peneira de $53 \mu \mathrm{m}$, com o auxílio de jato de água. O material retido na peneira, que consistiu na matéria orgânica particulada (MOP), foi seco em estufa, a $50^{\circ} \mathrm{C}$, até atingir peso constante, quantificado em relação à sua massa, moído em grau de porcelana e analisado em relação ao teor de $\mathrm{C}$ orgânico. As frações de carbono e nitrogênio foram analisadas conforme Tedesco et al. (1995), assim como as análises químicas e físicas do solo e as análises físico-químicas da cama de peru.

Os estoques de carbono orgânico total (COT) e particulado (COP), nitrogênio total (NT) e N na fração particulada (NP) foram calculados em massa equiva- lente de solo. Este método leva em conta a massa do solo dos tratamentos, em relação ao solo com menor massa, o que é tido como referência (Ellert \& Bettany 1995). Desta forma, o cálculo dos estoques baseou-se nas densidades de $0,84 \mathrm{~kg} \mathrm{dm}^{-3}$, para a profundidade de $0-5 \mathrm{~cm}$, e $0,90 \mathrm{~kg} \mathrm{dm}^{-3}$, para as profundidades de 5-10 cm e 10-20 cm do solo. Para o cálculo do estoque total de $\mathrm{C}$ e $\mathrm{N}$ e das frações, foi realizada a soma dos estoques, em cada camada amostrada.

Para o estudo de agregados via úmida, a metodologia foi adaptada de Silva \& Mielniczuk (1997). Duas subamostras de $50 \mathrm{~g}$ foram pesadas e colocadas em papel filtro, em potes plásticos com um filme de água, para que os agregados fossem umedecidos por capilaridade, durante um período de 16 horas. $\mathrm{O}$ conteúdo foi disposto em um conjunto de peneiras de malha com 2,00 mm, $1,00 \mathrm{~mm}, 0,50 \mathrm{~mm}, 0,25 \mathrm{~mm}$ e $0,125 \mathrm{~mm}$, sob agitação vertical, por 15 minutos. A quantidade de solo que passou da última malha da peneira para o vasilhame com água foi peneirada em malha de $0,105 \mathrm{~mm}$ e $0,053 \mathrm{~mm}$. O solo de cada peneira foi transferido para recipientes devidamente pesados e identificados, os quais foram levados à estufa, a $105^{\circ} \mathrm{C}$, até atingirem peso constante. Para avaliação da massa de agregados, foi realizada uma separação em três classes: micro $(<0,25 \mathrm{~mm})$, meso $(0,25-2,00 \mathrm{~mm})$ e macroagregados $(>2,00 \mathrm{~mm})$.

Os resultados das análises foram submetidos a análise de variância e, quando significativa, empregou-se a análise de regressão polinomial.

\section{RESULTADOS E DISCUSSÃO}

Os valores de $\mathrm{pH}$ se elevaram à medida em que foram adicionadas maiores quantidades de cama de peru ao solo (Tabela 1), sendo que o inverso ocorreu com a saturação por alumínio, que reduziu-se até $20,0 \mathrm{~cm}$ de profundidade. Com relação ao $\mathrm{pH}$, o aumento ocorreu, inicialmente, devido à aplicação de um resíduo ao solo (cama de peru) que possui $\mathrm{pH}$ próximo a 8,0. A relação inversa entre $\mathrm{pH}$ e saturação por alumínio era esperada, tendo-se em vista que este efeito é causado em $\mathrm{pH}$ a partir de 5,5, no qual ocorrem reações de hidrólise, aumentando as formas de alumínio com carga nula e promovendo a precipitação de $\mathrm{Al}^{3+}$. Além disto, compostos orgânicos de baixo peso molecular, e mesmo a matéria orgânica mais humificada, dispõem de poder para complexar o alumínio presente na solução do solo, reduzindo a concentração deste elemento (Salet 1998). 
Tabela 1. Atributos químicos de Latossolo Vermelho distroférrico sob sistema rotacionado de pastejo, em função de profundidades de amostragem e doses acumuladas de cama de peru (Portelândia, GO, 2011).

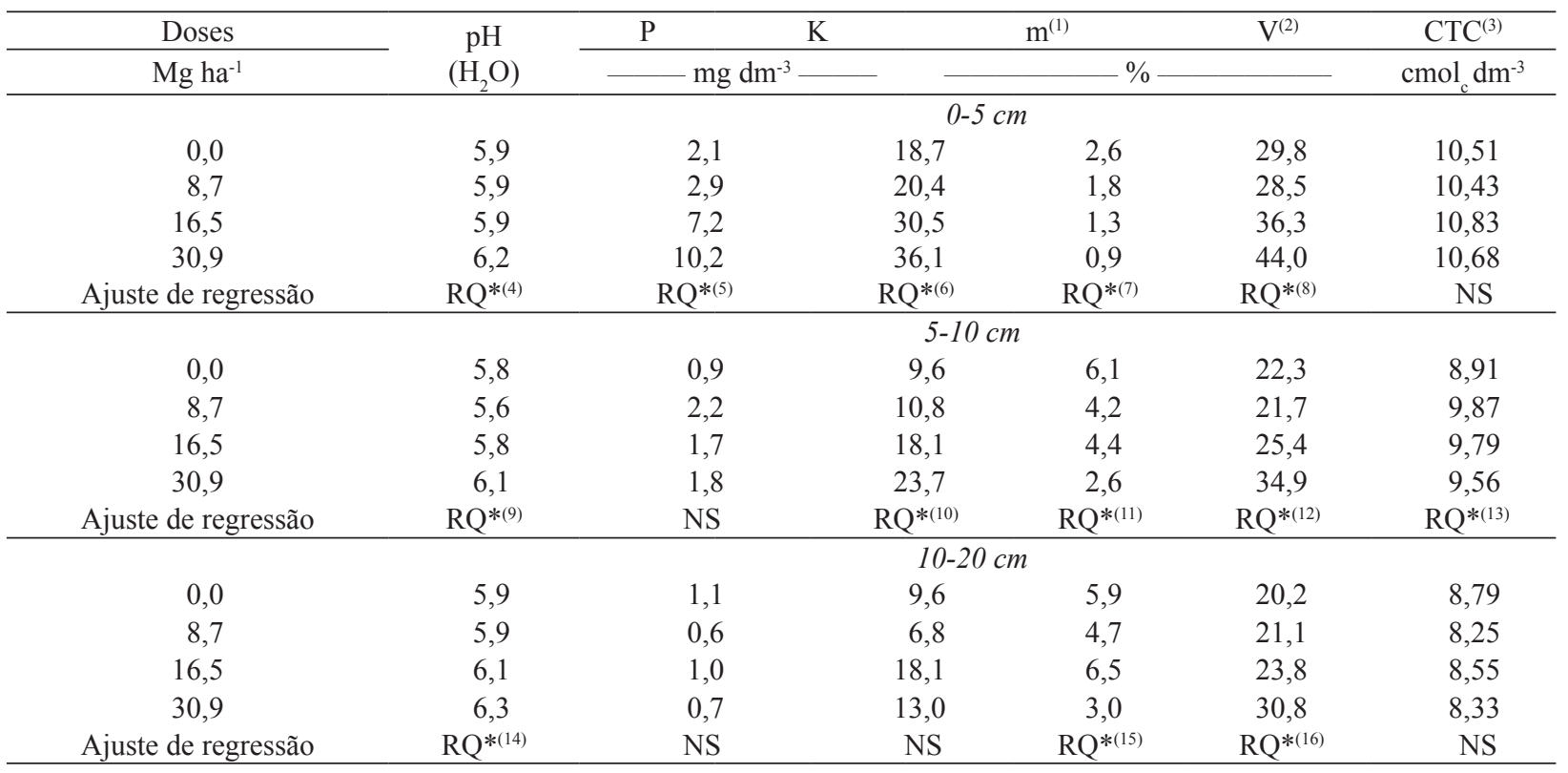

* Regressão quadrática significativa a 5\%; (1) Saturação por alumínio; ${ }^{(2)}$ Saturação por bases; ${ }^{(3)}$ Capacidade de troca de cátions; ${ }^{(4)} \mathrm{y}=5,95-0,009 \mathrm{x}+0,0005 \mathrm{x}^{2}\left(\mathrm{R}^{2}=0,99\right)$; ${ }^{(5)} \mathrm{y}=1,68+0,281 \mathrm{x}-0,0002 \mathrm{x}^{2}\left(\mathrm{R}^{2}=0,94\right) ;{ }^{(6)} \mathrm{y}=17,71+0,655 \mathrm{x}-0,0015 \mathrm{x}^{2}\left(\mathrm{R}^{2}=0,93\right) ;{ }^{(7)} \mathrm{y}=2,58-0,100 \mathrm{x}+0,0015 \mathrm{x}^{2}\left(\mathrm{R}^{2}=0,99\right) ;{ }^{(8)} \mathrm{y}=29,00+0,117 \mathrm{x}+0,0123 \mathrm{x}^{2}$ $\left(\mathrm{R}^{2}=0,99\right) ;{ }^{(9)} \mathrm{y}=5,81-0,021 \mathrm{x}+0,0011 \mathrm{x}^{2}\left(\mathrm{R}^{2}=0,62\right) ;{ }^{(10)} \mathrm{y}=8,94+0,426 \mathrm{x}+0,0019 \mathrm{x}^{2}\left(\mathrm{R}^{2}=0,94\right) ;{ }^{(11)} \mathrm{y}=8,94+0,426 \mathrm{x}+0,0019 \mathrm{x}^{2}\left(\mathrm{R}^{2}=0,89\right) ;{ }^{(12)} \mathrm{y}=8,94+0,426 \mathrm{x}+$ $0,0019 \mathrm{x}^{2}\left(\mathrm{R}^{2}=0,99\right) ;{ }^{(13)} \mathrm{y}=8,94+0,426 \mathrm{x}+0,0019 \mathrm{x}^{2}\left(\mathrm{R}^{2}=0,88\right) ;{ }^{(14)} \mathrm{y}=5,85+0,010 \mathrm{x}+0,0001 \mathrm{x}^{2}\left(\mathrm{R}^{2}=0,86\right) ;{ }^{(15)} \mathrm{y}=5,49+0,090 \mathrm{x}-0,0053 \mathrm{x}^{2}\left(\mathrm{R}^{2}=0,64\right) ;{ }^{(16)} \mathrm{y}=$ $20,08+0,066 \mathrm{x}+0,0091 \mathrm{x}^{2}\left(\mathrm{R}^{2}=0,99\right)$.

Whalen et al. (2000) também observaram aumento do $\mathrm{pH}$ e redução do alumínio tóxico, com a aplicação de resíduos ao solo. Nesta linha, Miyazawa et al. (1993) comentam que ocorreu redução do alumínio e da sua toxidez, devido à decomposição dos resíduos que liberam ácidos orgânicos de baixo peso molecular (cítrico, oxálico, málico, etc.), os quais formam complexos que reduzem a atividade do alumínio no solo. Estes efeitos ocorrem de maneira semelhante à aplicação de corretivos ao solo e podem ter efeito prolongado, por diversos anos, mesmo em camadas abaixo da superficial.

Estudos de Hue \& Amien (1989) demonstraram que a aplicação de esterco de aves ao solo promoveu incremento de compostos orgânicos de baixo peso molecular, que se movimentam no perfil do solo, promovendo complexação do alumínio tóxico. Há de se salientar que este efeito somente é possível com a adição de grandes quantidades de carbono (resíduos), o que ficou evidente no presente trabalho, tendo-se em vista que os efeitos ocorrem com as maiores quantidades de cama de peru aplicadas.

Os teores de $\mathrm{P}$ foram influenciados pela aplicação de cama de peru na camada de 0-0,05 m (Tabela 1), ocorrendo aumento dos teores com o aumento da dose de cama. Este efeito é bastante importante, do ponto de vista da disponibilidade de $\mathrm{P}$ para a pastagem, uma vez que, neste solo, a fixação de $\mathrm{P}$ tende a ser bastante alta, o que dificulta o aumento nos teores disponíveis do elemento.

Nas camadas de 0,05-0,20 $\mathrm{m}$ de profundidade, não houve aumento nos teores de $\mathrm{P}$, uma vez que o P apresenta baixa mobilidade no solo. Ainda, o aumento de $\mathrm{pH}$ associado a maiores aplicações de $\mathrm{P}$, nas maiores doses de cama de aviário, permite maior disponibilidade do nutriente, sendo classificado com o teor médio.

$\mathrm{Na}$ área sem aplicação de dejeto de aviário, o teor de P no solo é classificado como muito baixo (Sousa \& Lobato 2004). O aumento nos teores de $\mathrm{P}$ disponível demonstra que o dejeto de aviário favoreceu incrementos em maiores níveis, na fração lábil do P. Scherer et al. (2010), trabalhando com dejetos de suínos, encontraram aumento dos teores de $\mathrm{P}$ em latossolos e cambissolos, na camada de 0-0,05 m, corroborando os dados do presente trabalho.

Os teores de $\mathrm{K}$ apresentaram tendência de aumento semelhante aos de $\mathrm{P}$, com a adição de cama de peru, entretanto, com efeito, também, na camada de 0,05-0,10 m (Tabela 1). Na camada superficial, 
observaram-se valores variando de $18,7 \mathrm{mg} \mathrm{dm}^{-3}$, para a referência sem aplicação de cama de peru, a $36,16 \mathrm{mg} \mathrm{dm}^{-3}$, o que representa aumento de, aproximadamente, $100 \%$. Este aumento em superfície refletiu nos teores de $\mathrm{K}$ em profundidade, uma vez que houve aumento nos teores, na camada de 0,10-0,20 m, devido à grande mobilidade que $\mathrm{o} K$ apresenta. Nesta mesma linha, Scherer et al. (2010) observaram movimentação do $\mathrm{K}$ até a profundidade de 1,1 m e Werle et al. (2008), em estudos com latossolo, verificaram que a movimentação não relaciona-se com os teores de argila e sim com os teores de $\mathrm{K}$ adicionados à superfície.

A saturação por bases foi influenciada pela aplicação de cama de peru em todas as camadas avaliadas (Tabela 1), havendo incremento nos seus valores, com o aumento da dose de cama aplicada. Isto evidencia aumentos das bases trocáveis até a camada de $0,20 \mathrm{~m}$, que são favorecidos pela aplicação de cama de peru, pois há incremento na mobilidade destas bases.

Observou-se, com relação à saturação por bases, que a magnitude dos efeitos tende a diminuir com a profundidade (Tabela 1), com valores variando de $29,8 \%$ a $44,0 \%$ (camada de $0-0,05 \mathrm{~m}$ ), $22,3 \%$ a $34,9 \%$ (camada de 0,05-0,10 m) e 20,2\% a 30,8\% (camada de 0,10-0,20 m), para a testemunha sem aplicação de cama e a maior dose de cama de peru $\left(30,9 \mathrm{Mg} \mathrm{ha}^{-1}\right)$, respectivamente. No entanto, mesmo que em menor magnitude, há importante efeito da cama de peru aplicada em superfície no aumento das bases trocáveis, até a profundidade de $0,20 \mathrm{~m}$, com consequência direta sobre a saturação por bases (Tabela 1). Este efeito é benéfico nestes solos sob pastagem, uma vez que a gramínea utilizada necessita de saturação por bases de, aproximadamente, $35 \%$, o que é atingido com aplicações sucessivas de cama de peru.

O acúmulo crescente das doses de cama de peru não influenciou no estado de agregação do solo (Tabela 2), independentemente da camada avaliada. Houve pequena variação entre os tratamentos, o que não foi suficiente para demonstrar diferenças entre as doses aplicadas. Isto decorre do fato de que a cultura utilizada é uma gramínea que favorece grande acúmulo de resíduo orgânico no solo e possui sistema radicular extremamente agressivo, o que não depende, diretamente, da aplicação de cama de peru. Outro fator de extrema importância é a grande quantidade de óxidos presentes neste solo, o que faz com que a matéria orgânica adicionada tenha papel secundário na agregação (Souza et al. 2009).
Tabela 2. Distribuição de agregados estáveis em água (\%), em diferentes profundidades, em Latossolo Vermelho distroférrico sob sistema de pastejo rotacionado, com doses acumuladas de cama de peru (Portelândia, GO, 2011).

\begin{tabular}{|c|c|c|c|c|c|}
\hline \multirow{2}{*}{$\begin{array}{c}\text { Tamanho de } \\
\text { classes de } \\
\text { agregados }\end{array}$} & \multicolumn{4}{|c|}{$\begin{array}{l}\text { Doses de cama de peru } \\
\mathrm{Mg} \mathrm{ha}^{-1}\end{array}$} & \multirow{2}{*}{$\begin{array}{l}\text { Ajuste } \\
\text { de } \\
\text { regressão }\end{array}$} \\
\hline & 0,0 & 8,7 & 16,5 & 30,9 & \\
\hline \multicolumn{6}{|c|}{$0-5 \mathrm{~cm}$} \\
\hline$<0,25 \mathrm{~mm}$ & 8,0 & 11,0 & 22,0 & 6,0 & ns \\
\hline $0,25 \mathrm{~mm}$ a $2,0 \mathrm{~mm}$ & 20,0 & 24,0 & 16,0 & 17,0 & ns \\
\hline$>2 \mathrm{~mm}$ & 72,0 & 65,0 & 62,0 & 77,0 & ns \\
\hline \multicolumn{6}{|c|}{$5-10 \mathrm{~cm}$} \\
\hline$<0,25 \mathrm{~mm}$ & 6,0 & 10,0 & 15,0 & 7,0 & ns \\
\hline $0,25 \mathrm{~mm}$ a $2,0 \mathrm{~mm}$ & 24,0 & 21,0 & 20,0 & 26,0 & ns \\
\hline$>2 \mathrm{~mm}$ & 70,0 & 69,0 & 65,0 & 67,0 & ns \\
\hline \multicolumn{6}{|c|}{$10-20 \mathrm{~cm}$} \\
\hline$<0,25 \mathrm{~mm}$ & 9,0 & 12,0 & 6,0 & 7,0 & ns \\
\hline $0,25 \mathrm{~mm}$ a $2,0 \mathrm{~mm}$ & 27,0 & 25,0 & 19,0 & 23,0 & ns \\
\hline$>2 \mathrm{~mm}$ & 64,0 & 63,0 & 75,0 & 70,0 & ns \\
\hline
\end{tabular}

ns = Não significativo.

Os estoques de carbono orgânico total (COT) aumentaram com a aplicação de $16,5 \mathrm{Mg} \mathrm{ha}^{-1} \mathrm{e}$ $30,9 \mathrm{Mg} \mathrm{ha}^{-1}$ de cama de peru, na camada de $0-20 \mathrm{~cm}$ (Figura 1a), proporcionando incremento de 11,84\%, na maior dose, e de $15,64 \%$, na dose intermediária, equivalendo a um acréscimo de $8,33 \mathrm{Mg} \mathrm{ha}^{-1} \mathrm{e}$ $11,0 \mathrm{Mg} \mathrm{ha}^{-1}$, respectivamente, quando comparado com o menor estoque de $\mathrm{C}$ (menor dose).

Costa et al. (2008) também verificaram aumento dos estoques de carbono, com o aumento da dose de cama de peru aplicada ao solo. Scherer et al. (2007) observaram aumento no teor de matéria orgânica, no decorrer do tempo, utilizando esterco líquido de suínos. Este fato poder ser atribuído ao não revolvimento do solo e, consequentemente, à não incorporação do resíduo orgânico, fazendo com que a mineralização da matéria orgânica ocorresse de forma mais lenta, devido à menor exposição da mesma aos micro-organismos do solo, visto que a área utilizada encontrava-se sem revolvimento desde a implantação.

Com relação ao nitrogênio total, houve resposta semelhante, entretanto, com ajuste linear, no qual, com o aumento das doses de cama de peru, houve incrementos nos estoques de nitrogênio total e nitrogênio na matéria orgânica particulada (Figura 2). Este fenômeno já era esperado, devido aos altos teores de $\mathrm{N}(3,2 \%)$ presentes na cama de peru, o que chega a adicionar ao solo, aproximadamente, $1.000 \mathrm{~kg}$ de N, 
na maior dose aplicada. Isto possibilita aumento nos teores de $\mathrm{N}$ total e particulado no solo, além de suprir altas quantidades de $\mathrm{N}$ para a pastagem.

Os estoques de carbono orgânico particulado (COP) foram superiores, com a ausência de aplicação de resíduo e com a utilização de três doses consecutivas (Figura 1b). A maior dose utilizada, provavelmente, aumentou a produção da forrageira, contribuindo para o incremento do carbono da fração particulada. A fração particulada do COT é tida como a porção mais sensível ao manejo (Souza et al. 2009, Conte et al. 2011), demonstrando a influência da aplicação do resíduo orgânico. A aplicação da cama de peru parece ter estimulado a decomposição da fração particulada da matéria orgânica, reduzindo seu estoque. Por esta fração ser considerada mais lábil (Conte et al. 2011), serve como fonte de carbono para a microbiota do solo, sendo este processo acelerado pela adição de $\mathrm{N}$ e $\mathrm{P}$ fornecidos pela cama de peru, favorecendo a decomposição da mesma. Talvez esta redução esteja relacionada com a única aplicação realizada na área e com o tempo em que foi feita a amostragem (cerca de um ano depois da aplicação). No entanto, o estoque tende a se recuperar com o tempo e com as doses de cama, que promovem maior crescimento da forrageira.

Esta fração mostrou-se bastante sensível, também, ao manejo do pastejo adotado. Souza et al. (2009), avaliando um latossolo no Sul do Brasil, observaram que, quando a intensidade de pastejo

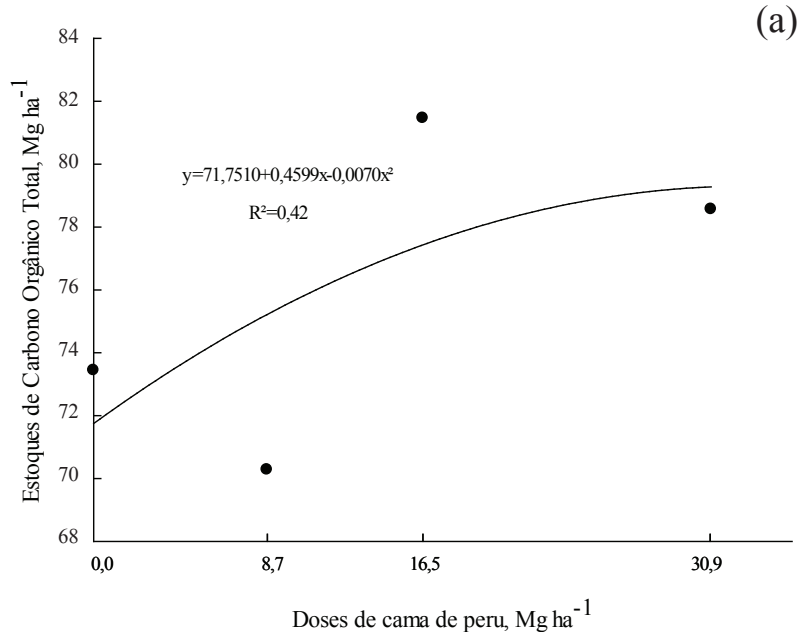

(a)

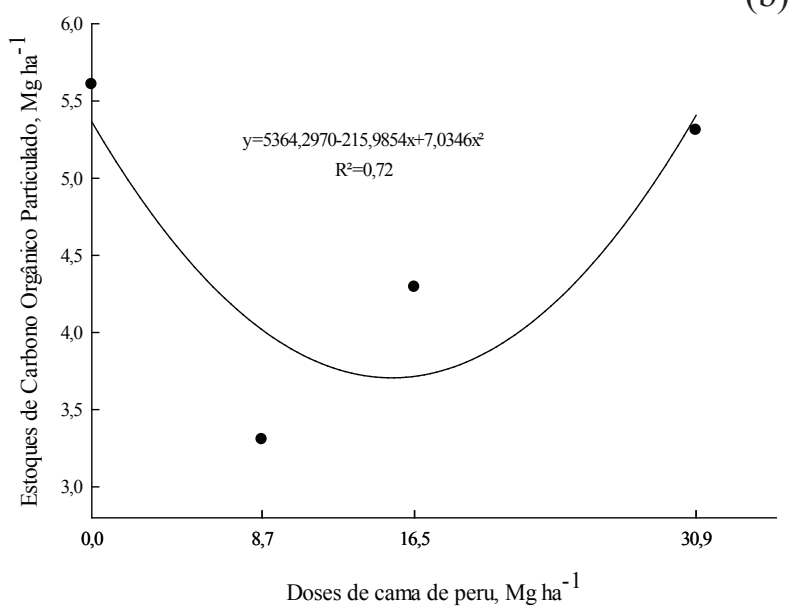

Figura 1. Estoque de carbono orgânico total (a) e carbono orgânico particulado (b), na camada de 0-20 cm, em Latossolo Vermelho distroférrico sob sistema de pastejo rotacionado, com doses acumuladas de cama de peru (Portelândia, GO, 2011).
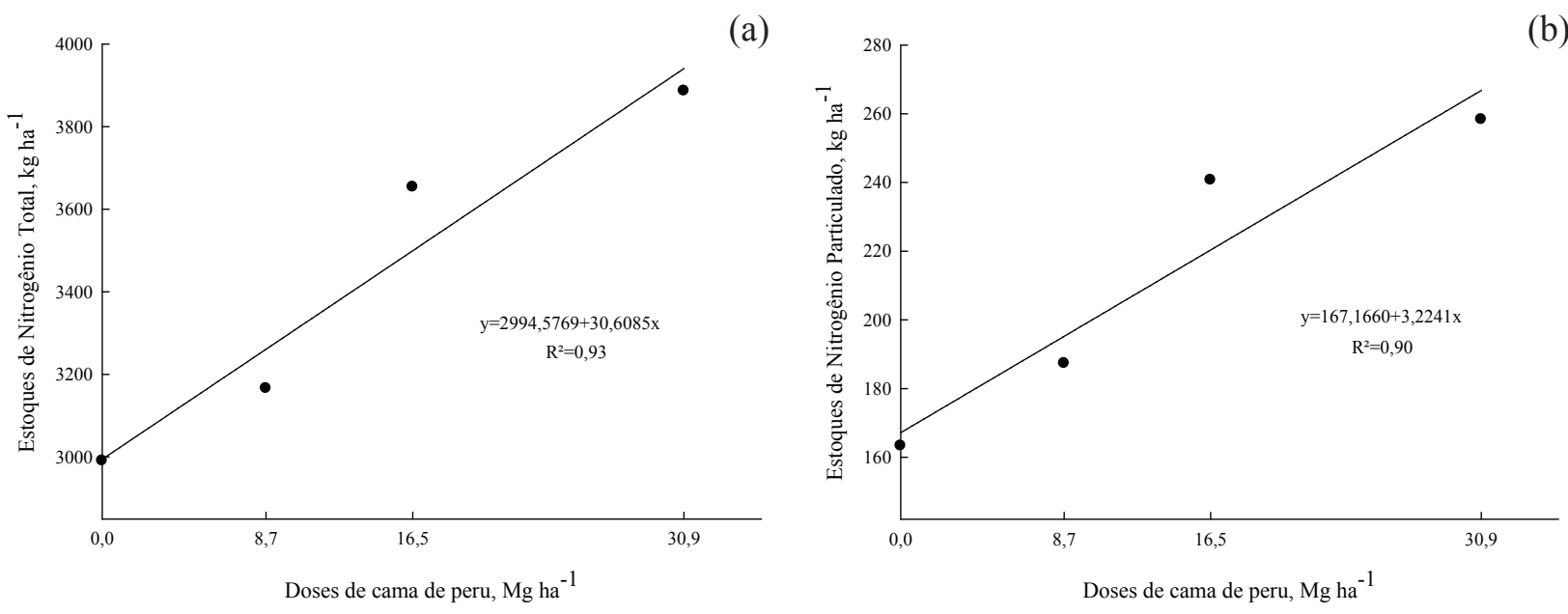

Figura 2. Estoques de nitrogênio total (a) e nitrogênio na matéria orgânica particulada (b), na camada de 0-20 cm, em Latossolo Vermelho distroférrico sob sistema de pastejo rotacionado, com doses acumuladas de cama de peru (Portelândia, GO, 2011). 
foi maior ( $0,10 \mathrm{~m}$ do solo), os estoques desta fração apresentaram redução de $5,0 \mathrm{Mg} \mathrm{ha}^{-1}$, em relação à ausência de pastejo. Em um argissolo sob pastagem natural, foi verificada redução dos estoques de COP superior a 4,0 Mg ha-1 , quando a intensidade de pastejo ocorreu de forma acentuada, em relação à ausência de pastejo, em experimento de longa duração (Conte et al. 2011).

As doses de cama de peru alteraram os valores de carbono da biomassa (C-BM) e nitrogênio da biomassa (N-BM), com os valores do carbono da biomassa microbiana variando de $442 \mu \mathrm{g} \mathrm{C}$ g solo $^{-1}$ a $1968 \mu \mathrm{g} \mathrm{C} \mathrm{g} \mathrm{solo-1}$, para a ausência de aplicação de cama de peru e a dose de $8,7 \mathrm{Mg} \mathrm{ha}^{-1}$, respectivamente (Tabela 3). Estes teores são mais elevados que os encontrados por Souza et al. (2006), fato que pode ser atribuído à grande disponibilidade de resíduo prontamente mineralizável, e as gramíneas apresentaram maior efeito rizosférico, disponibilizando substratos orgânicos, além da ausência de revolvimento do solo (Matsuoka et al. 2003).

O nitrogênio da biomassa microbiana (N-BM) variou de $3,7 \mu \mathrm{g} \mathrm{N} \mathrm{g} \mathrm{solo}{ }^{-1}$ a $8,4 \mu \mathrm{g} \mathrm{N}$ g solo ${ }^{-1}$, para as doses de $8,7 \mathrm{Mg} \mathrm{ha}^{-1}$ e $16,5 \mathrm{Mg} \mathrm{ha}^{-1}$, respectivamente (Tabela 3). Os baixos valores encontrados de N-BM corroboram os resultados de Gama-Rodrigues (1997), que observou menor acúmulo de N-BM em solos que receberam aplicação de materiais com alto teor de $\mathrm{N}$ e de rápida decomposição. Solos com teores elevados de $\mathrm{N}$ tendem a uma menor imobilização, pois a quantidade disponível seria suficiente para atender à atividade microbiana e ao processo de decomposição da matéria orgânica do solo (Gama-Rodrigues 1999).

A biomassa microbiana, como constituinte da matéria orgânica do solo, permite avaliar perturba- ções rápidas, ocasionadas pelo manejo do solo (Alvarez et al.1995). Gama-Rodrigues (1999) observou valores para C-BM compreendidos entre $2 \%$ e $4 \%$ do COT, com teores inferiores a estes representando perdas de $\mathrm{C}$ no sistema, sendo observada a menor proporção na ausência da aplicação de cama de peru e a maior na menor dose (Tabela 3).

Quanto à respiração microbiana $\left(\mathrm{C}-\mathrm{CO}_{2}\right)$, as perdas de $\mathrm{C}$ nos sistemas foram semelhantes em todas as doses aplicadas (Tabela 3), demonstrando estabilidade na respiração, visto que, na época em que foi realizada a coleta do solo, estava iniciando-se o período seco. No entanto, houve tendência de queda na taxa respiratória, quando avaliadas a menor e maior doses de dejeto de aviário, o que aponta perda de $\mathrm{C}$ no solo, provavelmente devido ao acúmulo do dejeto, que favoreceu maior atividade microbiana.

Os menores valores de $q \mathrm{CO}_{2}$ foram encontrados na menor dose de cama de peru (Tabela 3). Este fato pode estar associado ao estímulo à decomposição do $\mathrm{C}$, devido à aplicação da primeira dose, assim como aconteceu com o COP. Souza et al. (2006) encontraram valores para pastagem superiores ao encontrado no presente estudo, destacando a pouca perda de carbono no sistema. Segundo os mesmos autores, estes valores representam a eficiência da população microbiana em utilizar carbono para a sua sobrevivência, onde altas perdas indicam ineficiência da população.

\section{CONCLUSÕES}

1. Aplicações sequenciais de cama de peru promoveram melhorias na fertilidade do solo, com aumento de $\mathrm{pH}, \mathrm{P}, \mathrm{K}$ e saturação por bases e diminuição na saturação por alumínio.

Tabela 3. Valores de carbono da biomassa (C-BM), nitrogênio da biomassa (N-BM), respiração microbiana $\left(\mathrm{C}_{-} \mathrm{CO}_{2}\right)$, quociente microbiano (x 100) (BM/COT) e quociente metabólico $\left(q \mathrm{CO}_{2}\right)$, na camada de 0-10 cm, em Latossolo Vermelho distroférrico sob sistema de pastejo rotacionado, com doses acumuladas de cama de peru (Portelândia, GO, 2011).

\begin{tabular}{cccccc}
\hline Doses & $\mathrm{C}-\mathrm{BM}$ & $\mathrm{N}-\mathrm{BM}$ & $\mathrm{C}_{-\mathrm{CO}_{2}}$ & $\mathrm{BM} / \mathrm{COT}$ & $q \mathrm{CO}_{2}$ \\
\hline $\mathrm{Mg} \mathrm{ha}^{-1}$ & $\mu \mathrm{g} \mathrm{C} \mathrm{g} \mathrm{solo}^{-1}$ & $\mu \mathrm{g} \mathrm{N} \mathrm{g} \mathrm{solo}^{-1}$ & $\mathrm{mg} \mathrm{CO}_{2} \mathrm{~g} \mathrm{~h}^{-1}$ & & $\begin{array}{c}\mathrm{mg} \mathrm{CO}_{2} \mathrm{~g} \mathrm{~h}^{-1} \\
\mu \mathrm{g} \mathrm{C} \mathrm{solo}^{-1}\end{array}$ \\
\hline 0,0 & 442,0 & 6,9 & 12,9 & 0,9 & 0,032 \\
8,7 & $1.968,0$ & 3,7 & 10,0 & 4,6 & 0,005 \\
16,5 & 677,0 & 8,4 & 12,6 & 1,4 & 0,012 \\
30,9 & 853,0 & 5,2 & 13,7 & 1,8 & 0,017 \\
Ajuste de Regressão & $\mathrm{NS}$ & $\mathrm{NS}$ & $\mathrm{RQ}{ }^{*(1)}$ & $\mathrm{NS}$ & $\mathrm{RQ}{ }^{*(2)}$ \\
\hline
\end{tabular}

* Regressão quadrática significativa a $5 \% .{ }^{(1)} \mathrm{y}=12,4650-0,1897 \mathrm{x}+0,0077 \mathrm{x}^{2}\left(\mathrm{R}^{2}=0,54\right) ;{ }^{(2)} \mathrm{y}=0,0282-0,0019 \mathrm{x}+0,00005269 \mathrm{x}^{2}\left(\mathrm{R}^{2}=0,47\right)$. 
2. Doses crescentes de cama de peru favoreceram o aumento nos teores do estoque de carbono orgânico, nitrogênio total e nitrogênio particulado.

3. A aplicação de menores doses de cama de peru estimulou a atividade microbiana do solo, promovendo a mineralização da fração particulada da matéria orgânica.

4. A agregação do solo foi pouco influenciada pela aplicação de cama de peru ao solo sob pastagem de Brachiaria decumbens, com pastejo rotacionado, em Latossolo Vemelho distroférrico.

\section{REFERÊNCIAS}

ALEF, K.; NANNIPIERI, P. (Eds.). Methods in applied soil microbiology and biochemistry. London: Academic Press, 1995.

ALVAREZ, R. et al. Soil organic carbon, microbial biomass and $\mathrm{C}-\mathrm{CO}_{2}$ production from three tillage systems. Soil \& Tillage Research, Amsterdam, v. 33, n. 1, p. 17-28, 1995.

ANDERSON, J. P. E.; DOMSCH, K. H. The metabolic quotient $\left(q \mathrm{CO}_{2}\right)$ as a specific activity parameter to assess the effects of environmental conditions, such as $\mathrm{pH}$, on the microbial biomass of forest soils. Soil Biology and Biochemistry, Oxford, v. 25, n. 3, p. 393-395, 1993.

ANDREOLA, F.; COSTA, L. M.; OLSZEVSKI, N. Influência da cobertura vegetal de inverno e da adubação orgânica e, ou, mineral sobre as propriedades físicas de uma terra roxa estruturada. Revista Brasileira de Ciência do Solo, Viçosa, v. 24, n. 3, p. 857-865, 2000.

BRASIL. Ministério da Agricultura, Pecuária e Abastecimento. Gabinete do Ministro. Instrução Normativa $\mathrm{n}^{\circ} 25$, de 23 de julho de 2009. Diário Oficial da República Federativa do Brasil, Brasília, DF, 28 jul. 2009. Seção 1, p. 20.

BAYER, C. et al. Armazenamento de carbono em frações lábeis da matéria orgânica de um Latossolo Vermelho sob plantio direto. Pesquisa Agropecuária Brasileira, Brasília, DF, v. 39, n. 7, p. 677-683, 2004.

CAMBARDELLA, C. A.; ELLIOT, E. T. Particulate soil organic matter changes across a grassland cultivation sequence. Soil Science Society of America Journal, Madison, v. 56, n. 3, p. 777-783, 1992.

CONTE, O. et al. Densidade, agregação e frações de carbono de um argissolo sob pastagem natural submetida a níveis de ofertas de forragem por longo tempo. Revista Brasileira de Ciência do Solo, Viçosa, v. 35, n. 2, p. 579587, 2011.

CORAZZA, E. J. et al. Comportamento de diferentes sistemas de manejo como fonte ou depósito de carbono em relação à vegetação de Cerrado. Revista Brasileira de Ciência do Solo, Viçosa, v. 23, n. 2, p. 425-432, 1999.

COSTA, A. M. et al. Estabilidade de agregados de um Latossolo Vermelho tratado com cama de peru. Ciência e Agrotecnologia, Lavras, v. 32, n. 1, p. 73-79, 2008.

COSTA, A. M. et al. Potencial de recuperação física de um Latossolo Vermelho, sob pastagem degradada, influenciado pela aplicação de cama de frango. Ciência e Agrotecnologia, Lavras, v. 33, ed. esp., p. 1991-1998, 2009.

ELLERT, B. H.; BETTANY, J. R. Calculation of organic matter and nutrients stored in soils under contrasting management regimes. Canadian Journal of Soil Science, Ottawa, v. 75, n. 4, p. 529-538, 1995.

GAMA-RODRIGUES, E. F. Biomassa microbiana e ciclagem de nutrientes. In: SANTOS, G. A.; CAMARGO, F. A. O. (Eds.). Fundamentos da matéria orgânica do solo: ecossistemas tropicais \& subtropicais. Porto Alegre: Gênesis, 1999. p. 227-243.

GAMA-RODRIGUES, E. F. Carbono e nitrogênio da biomassa microbiana do solo e da serrapilheira de povoamentos de eucalipto. 1997. $108 \mathrm{f}$. Tese (Doutorado em Ciência do Solo) - Universidade Federal Rural do Rio de Janeiro, Seropédica, 1997.

HUE, N. V.; AMIEN, I. Aluminum detoxification with green manures. Communication Soil Science Plant Analysis, New York, v. 20, n. 15/16, p. 1499-1511, 1989.

MATSUOKA, M.; MENDES, I. C.; LOUREIRO, M. F. Biomassa microbiana e atividade enzimática em solos sob vegetação nativa e sistemas agrícolas anuais e perenes na região de Primavera do Leste (MT). Revista Brasileira de Ciência do Solo, Viçosa, v. 27, n. 3, p. 425-433, 2003.

MIYAZAWA, M.; PAVAN, M. A.; CALEGARI, A. Efeito de material vegetal na acidez do solo. Revista Brasileira de Ciência do Solo, Campinas, v. 17, n. 3, p. 411-416, 1993.

SALET, R. L. Toxidez de alumínio no sistema plantio direto. 1998. 109 f. Tese (Doutorado em Ciência do Solo) - Universidade Federal do Rio Grande do Sul, Porto Alegre, 1998.

SCHERER, E. E.; BALDISSERA, I. T.; NESI, C. N. Propriedades químicas de um Latossolo Vermelho sob plantio direto e adubação com esterco de suínos. Revista Brasileira de Ciência do Solo, Viçosa, v. 31, n. 1, p. 123131, 2007.

SCHERER, E. E.; NESI, C. N.; MASSOTTI, Z. Atributos químicos do solo influenciados por sucessivas aplicações de dejetos suínos em áreas agrícolas de Santa Catarina. Revista Brasileira de Ciência do Solo, Viçosa, v. 34, n. 4, p. 1375-1383, 2010. 
SILVA, I. F.; MIELNICZUK, J. Avaliação do estado de agregação do solo afetado pelo uso agrícola. Revista Brasileira de Ciência do Solo, Viçosa, v. 21, n. 2, p. 313319, 1997.

SOUSA, D. M. G.; LOBATO, E. Cerrado: correção do solo e adubação. 2. ed. Planaltina: Embrapa Cerrados, 2004.

SOUZA, E. D. et al. Frações do carbono orgânico, biomassa e atividade microbiana em um Latossolo Vermelho sob Cerrado submetido a diferentes sistemas de manejos e usos do solo. Acta Scientiarum Agronomy, Maringá, v. 28, n. 3, p. 323-329, 2006.

SOUZA, E. D. et al. Estoques de carbono orgânico e de nitrogênio no solo em sistema de integração lavourapecuária em plantio direto, submetido a intensidades de pastejo. Revista Brasileira de Ciência do Solo, Viçosa, v. 33, n. 6, p. 1829-1836, 2009.
TEDESCO, M. J. et al. Análise de solo, plantas e outros materiais. 2. ed. rev. e ampl. Porto Alegre: UFRGS, 1995. (Boletim técnico, 5).

VANCE, E. D.; BROOKES, P. C.; JENKINSON, D. S. An extraction method for measuring microbial biomass C. Soil Biology and Biochemistry, Amsterdam, v. 19, n. 6, p. 703-707, 1987.

WERLE, R.; GARCIA, R. A.; ROSOlEM, C. A. Lixiviação de potássio em função da textura e da disponibilidade do nutriente no solo. Revista Brasileira de Ciência do Solo, Viçosa, v. 32, n. 6, p. 2297-2305, 2008.

WHALEN, J. K. et al. Cattle manure amendments can increase the $\mathrm{pH}$ of acid soils. Soil Science Society of America Journal, Madison, v. 64, n. 3, p. 962-966, 2000. 